in neonates is $35 \mathrm{mg} / \mathrm{kg} / 24 \mathrm{hrs}$ however safe brain levels are unknown.

Objective To determine the PG levels in MRS of infants with NE.

Design/methods MRS between July 2010 and August 2013 were reviewed in infants with NE (PRESS sequence TE: 288ms) All MRS spectra were reviewed by an MR Physicist. Cases with an observable doublet at $1.1 \mathrm{ppm}$ were reprocessed with Tarquin V4.3.2 using a simulated basis set the included PG and referenced to unsurpassed water signal to obtain institutional units of concentration.

Results 29 infants with NE. MRI was performed at mean age of 120 hrs (35-197 hrs) Diagnosis HIE (27), Congenital lactic acidosis (1) GBS meningitis (1) MCA infarction (1) PG was present in $24 \%$ of infants $(n=7)$. The mean level on MRS was $10.76 \mathrm{mM}(2.11-26.48)$.

All infants with PG peaks received $40 \mathrm{mg} / \mathrm{kg} \mathrm{PhB}$, and $18 \mathrm{mg} /$ $\mathrm{kg} \mathrm{Ph}$ and 6/7 received Clonazepam. No PG group required less anticonvulsants $(13.6 \%$ no treatment, 63\% $\mathrm{PhB}, 23 \% \mathrm{PhB}$ and $\mathrm{Ph})$.

Conclusions PG is detected on MRS in NE infants.

The level may correlate with underlying diagnosis. PG accumulation may have clinical implications which need to be further investigated. Additionally PG must be correctly differentiated from lactate on MRS.

\section{P0-0411 QUANTITVE AMPLITUDE INTEGRATED ELECTROENCEPHALOGRAPHY ANALYSIS IN VERY LOW BIRTH WEIGHT INFANTS ON FIRST DAYS OF LIFE}

${ }^{1} \mathrm{~L}$ Karpinski, ${ }^{2} \mathrm{~J}$ Moczko, ${ }^{3} \mathrm{P}$ Niedbalski, ${ }^{1} \mathrm{~J}$ Szczapa, ${ }^{4} \mathrm{~A}$ Merritt, ${ }^{1} \mathrm{~J}$ Mazela. ${ }^{1}$ Department of Newborns' Infectious Diseases, Poznan University of Medical Sciences, Poznan, Poland; ${ }^{2}$ Department of Computer Science and Statistics, Poznan University of Medical Sciences, Poznan, Poland; ${ }^{3}$ Research and Development, Elimko Aparatura Medyczna, Warsaw, Poland; ' Department of Pediatrics, Loma Linda University, Loma Linda, USA

\subsection{6/archdischild-2014-307384.1056}

Background and aims Amplitude integrated electroencephalography (aEEG) is a tool for continuous brain function monitoring in NICU patients. The aEEG classification related to pathology and visually assessed by examiners is fully described. Nevertheless the quantitative analysis of these signal is still not well defined.

The aim was to check if a quantitative analysis of an aEEG can be a useful tool in early diagnosis of morbidities such as intraventricular haemorrhage (IVH), periventricular leukomalacia (PVL) and hemodynamically significant persistent ductus arteriosus (PDA).

Methods Very low birthweight newborns admitted to NICU in a first day of life were included. On 1st, 3rd and 10th day of life patients had been monitored with aEEG for $2 \mathrm{~h}$. A $1 \mathrm{~h}$ of stable recording was analysed. The aEEG power was analysed in 3 ranges (below $5 \mathrm{uV}$, between $5 \mathrm{uV}$ and $40 \mathrm{uV}$ and above $40 \mathrm{uV}$ ). The study group consisted of sick newborns with either IVH (III and IV grade), PVL or PDA (with surgical closure of PDA). The control group were children without these abnormalities. Groups were cross-matched according to gestational age. U Mann-Whitney test had been used.

Results There were 12 newborns in each: study and control group. There were 15 samples of an aEEG power from each patient. The aEEG power for children in study group was significantly lower on 1 st day of live for a range above $40 \mathrm{uV}(\mathrm{p}<$ $0,000000)$. On a 3rd day the aEEG power was significantly lower in a study group for range below $5 \mathrm{uV}(\mathrm{p}<0,000000)$ and higher for ranges between $5 \mathrm{uV}$ and $40 \mathrm{uV}$ and above $40 \mathrm{uV}(\mathrm{p}<$ $0,000000)$. On a 10 th day the power above $40 \mathrm{uV}$ was significantly lower in a study group $(\mathrm{p}=0,000006)$.

Conclusion Quantitive analysis of an aEEG could be a useful method of identifying high risk neonates on a first and 10th day of live. Diminished power above $40 \mathrm{uV}$ reflects decreased CNS activity described as electrical bursts.

\section{PO-0412 RELATIONSHIP BETWEEN CEREBRAL AND SYSTEMIC PERFUSION, AND SHORT-TERM OUTCOMES IN INFANTS WITH PERINATAL ASPHYXIA}

${ }^{1}$ A Kondo, ${ }^{1}$ A Hirose, ${ }^{2}$ T Takami, ${ }^{1}$ D Sunohara, ${ }^{1} \mathrm{H}$ Kawashima. ${ }^{1}$ Pediatrics, Tokyo Medical University, Tokyo, Japan; ${ }^{2}$ Neonatology, Toho University, Tokyo, Japan

\subsection{6/archdischild-2014-307384.1057}

Background and aims The effects of haemodynamic changes on cerebral and systemic perfusion in infants with perinatal asphyxia are not well understood. We investigated the relationship between cerebral and systemic perfusion, and short-term outcome in infants with asphyxia.

Methods Ten infants (gestation age $>35$ weeks) with asphyxia (Apgar score $<7$ at $1 \mathrm{~min}$ ) were divided into 2 groups: those with hypoxic-ischaemic encephalopathy (HIE; HIE group, $\mathrm{n}=$ 4 ) and those without HIE (non-HIE group, $n=6$ ). Cerebral tissue oxygenation index (TOI) and cerebral fractional tissue oxygen extraction (FTOE) were measured by near-infrared spectroscopy (NIRS) at 12, 24, 48, and $72 \mathrm{~h}$ after birth. Superior vena cava (SVC) flow and left ventricular cardiac output (LVCO) were simultaneously measured by echocardiography.

Results TOI was significantly higher and FTOE was significantly lower in the HIE group $(\mathrm{n}=4)$ than in the non-HIE group ( $=6$ ) at all measurement time points. Although SVC flow and LVCO were not significantly different between the 2 groups, they were consistently higher in the HIE group than in the nonHIE group at all measurement time points. We found a positive correlation between SVC flow and LVCO in both groups, and between SVC flow and TOI in the non-HIE group.

Conclusions Combined bedside monitoring of TOI and FTOE by NIRS and SVC flow may be useful for evaluating secondary energy failure and disrupted regulation of brain circulation in infants with asphyxia.

\section{P0-0413 TRIGEMINAL ODOURS RELEASED BY HEALTHCARE PRODUCTS ACTIVATE OLFACTORY AND PAIN CORTICAL AREAS IN PRETERM AND FULL TERM NEWBORNS}

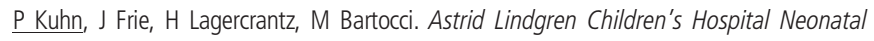
Research Unit Q2:07, Karolinska Institute, Stockholm, Sweden

\subsection{6/archdischild-2014-307384.1058}

Background/aim Hospitalised newborns are highly exposed to nosocomial odorous substances (OS) triggering possibly the intranasal trigeminal subsystem. Irritation of the nasal mucosa can induce pain and activations in pain processing areas in adults We aimed to evaluate cortical activation in trigeminal/olfactory and pain areas following OS exposure in newborns.

Methods Forty-four newborns (17 full-terms, 12 preterms at term PMA and 15 preterms $<33$ weeks PMA when tested) were 